\title{
Clonal diversity of Escherichia coli isolates from marketed beef in East Malaysia
}

\author{
K. Apun*, P.P. Chang, E.U.H Sim and V. Micky \\ Resource Biotechnology Programme, Faculty of Resource Science and Technology, University Malaysia Sarawak, \\ 94300, Kota Samarahan, Sarawak, Malaysia \\ *Author for correspondence: Tel.: +6082-671000 ext.7203, Fax: +6082-672275, E-mail: kasing@frst.unimas.my \\ Received 25 July 2005; accepted 31 October 2005
}

Keywords: beef, clonal diversity, Escherichia coli, East Malaysia, pulsed field gel electrophoresis

\begin{abstract}
Summary
Escherichia coli, including Shiga-like toxin producing E. coli (STEC), serogroup O157:H7 and E. coli O157, were isolated from raw beef marketed in Sarawak and Sabah, East Malaysia. Molecular subtyping by pulsed-field gel electrophoresis (PFGE) was performed on 51 confirmed E. coli isolates. Of the 51 isolates, five were E. coli O157:H7, four E. coli O157, two non-O157 STEC and 40 other E. coli isolates (non-STEC). Digestion of chromosomal DNA from these $E$. coli isolates with restriction endonuclease $X b a \mathrm{I}$ (5'-TCTAGA-3'), followed by PFGE, produced 45 restriction endonuclease digestion profiles (REDPs) of 10-18 bands. E. coli O157:H7 isolates from one beef sample were found to have identical PFGE profiles. In contrast, E. coli serogroup O157 from different beef samples displayed considerable differences in their PFGE profiles. These suggested that $E$. coli isolates of both serogroups were not closely related. A large variety of PFGE patterns among non-STEC isolates were observed, demonstrating a high clonal diversity of E. coli in the beef marketed in East Malaysia. The distance matrix values $(D)$, calculated showed that none of the pathogenic $E$. coli strains displayed close genetic relationship with the non-STEC strains. Based on the PFGE profiles, a dendrogram was generated and the isolates were grouped into five PFGE clusters (A-E). From the dendrogram, the most related isolates were E. coli O157:H7, grouped within cluster B. The STEC O157:H7 beef isolates were more closely related to the clinical E. coli $\mathrm{O} 157: \mathrm{H} 7$ isolate than the E. coli $\mathrm{O} 157: \mathrm{H} 7$ reference culture, EDL933. Cluster A, comprising many of other E. coli isolates was shown to be the most heterogeneous. PFGE was shown to possess high discriminatory power in typing pathogenic and non-pathogenic E. coli strains, and useful in studying possible clonal relationship among strains.
\end{abstract}

\section{Introduction}

Escherichia coli is a common commensal of the human gastrointestinal tract. However, under certain conditions strains of E. coli can cause disease. Shiga-like toxin-producing E. coli (STEC) has been implicated as the causative agent in several human diseases (Nataro \& Kaper 1998; Paton \& Paton 1998), with E. coli O157:H7 being the most well known among them. These diseases range from mild diarrhea, hemorrhagic colitis (HC), to complicated conditions, such as hemolytic-uremic syndrome (HUS) and thrombotic thrombocytopenic purpura (TTP). Cattle are generally considered to be the major reservoir of both E. coli O157 and non-O157 STEC (Bettelheim 2000). Due to the threat pathogenic E. coli pose to public health, characterisation of the E. coli in food samples is essential. Several different methods for E. coli characterisation are being used to identify genetic differences among $E$. coli isolates. This included ribotyping (Dalla-Costa et al. 1998), phage typing (Khakhria et al. 1990), randomly amplified polymorphic DNA (RAPD) (Hopkins \& Hilton 2000), and pulsed-field gel electrophoresis (Preston et al. 2000). Among these, pulsed-field gel electrophoresis (PFGE) was shown to produce highly discriminant genotyping and it was identified as the 'gold standard' for molecular subtyping of E. coli isolates (Preston et al. 2000; Rios et al. 1999). The purpose of this study was to evaluate by PFGE the genetic diversity as well as relatedness of E. coli O157:H7, E. coli O157, STEC and other E. coli strains (non-STEC) isolated from raw beef marketed in East Malaysia.

\section{Materials and methods}

\section{Bacterial strains}

Fifty-one E. coli isolates previously isolated from raw beef marketed in East Malaysia were used in this study. Confirmation of the isolates were conducted using the latex agglutination test with E. coli 0157 test kit (Oxoid), 
and using a multiplex PCR assay with four primers targeting the $s t x 1$, st $x 2$ (shiga-like toxin I and II), $R f b E$ (O antigen) and $f l i C_{h 7}(\mathrm{H} 7$ antigen) genes as described by Apun et al. (2003). Selection of isolates was based on their pathogenicity, phenotypic characteristics, and the source of isolation. These isolates included five E. coli O157:H7 isolates, four E. coli $\mathrm{O} 157$ isolates, two nonO157 STEC and 40 other E. coli isolates. The E. coli were isolated from raw beef purchased from six main towns in Sarawak, East Malaysia namely, Kuching (KC) Samarahan (SM), Sibu (SB), Sarikei (SA), Bintulu (BT), Miri (MI), and two main towns in Sabah, East Malaysia, namely Kota Kinabalu (KK) and Sandakan (SD). E. coli $\mathrm{O} 157: \mathrm{H} 7$ strain EDL933, was included as reference strain whereas E. coli O157:H7 strain SGH1, isolated from clinical sample, was included as comparison.

\section{Bacterial culture conditions}

All E. coli strains were cultured in LB (Luria Bertani) broth (Fluka) at $37^{\circ} \mathrm{C}$ with agitation overnight before being subjected to DNA preparation.

\section{DNA preparation}

DNA for PFGE analysis was prepared by the method of Thong \& Pang (1996), which required 3 days to complete, in contrast to the traditional protocol that requires 5 days to complete. Genomic DNA was prepared by embedding $E$. coli cells in agarose plugs (Ultrapure) and lysing the cells using $1 \mathrm{mg}$ lysozyme $/ \mathrm{ml}(2 \mathrm{ml}$ per plug, $1 \mathrm{ml}$ per subsequent plug) for $6 \mathrm{~h}$ at $37^{\circ} \mathrm{C}$, with gentle agitation. Then, the lysis solution was replaced with ES (0.5 M NAEDTA, $1 \%$ sarcosyl) solution containing $0.5 \mathrm{mg} / \mathrm{ml}$ proteinase $\mathrm{K}$ and incubated overnight at $50{ }^{\circ} \mathrm{C}$ with gentle shaking. The plugs were dialysed with sterile TE for five times at room temperature with agitation (EYEL4, Multi Shaker MMS). The first two washes were performed at $1 \mathrm{~h}$ interval. Subsequent three washes were done at $2 \mathrm{~h}$ intervals.

\section{Restriction endonuclease digestion}

The chromosomal DNA digestion was performed while still embedded in agarose. The restriction enzyme $X b a \mathrm{I}$ (Promega), a six base cutter (5'-TCTAGA-3'), was used to digest the DNA for each isolate. The enzyme was selected because it yielded the restriction patterns that have been most reproducible. Following the restriction enzyme digestion, the DNA plug was equilibrated with $1.0 \mathrm{ml}$ of $0.5 \times \mathrm{TBE}$ buffer on ice for $45 \mathrm{~min}$.

\section{PFGE}

The slice was then loaded into the well of $1.2 \%$ PulsedField Certified agarose (Bio-Rad) prepared in $0.5 \times \mathrm{TBE}$ buffer. PFGE of the digested DNA was carried out with a contour-clamped homogenous electric field apparatus
(CHEF DRIII, Bio-Rad). For gel electrophoresis, two program blocks were used: block 1, ramped pulse times of $15-30 \mathrm{~s}$ ( $7 \mathrm{~h}$ of electrophoretic run), followed by block 2, ramped pulse times of 2.2-56.0 s $(15 \mathrm{~h}$ of electrophoretic run). Other parameters included: voltage of $200 \mathrm{~V}(6 \mathrm{~V} / \mathrm{cm})$, an electric field angle of $120^{\circ}$ and a temperature of $14{ }^{\circ} \mathrm{C}$. Then, the gel was stained with $0.5 \mu \mathrm{g} / \mathrm{ml}$ ethidium bromide (Sigma) before viewing under an u.v. transluminator (Vilber Lourmat). The PFG lambda ladder (New England Biolabs) consisting of concatemers starting at $48.5 \mathrm{~kb}$ and increasing to approximately $1000 \mathrm{~kb}$ were used as molecular markers to estimate the size of the DNA fragments. Digested DNA of E. coli O157:H7 strain EDL933 was included in every gel for standardisation and as a reference.

\section{Data analysis}

PFGE bands were scored for presence (1) or absence (0) of a distinct band. PFGE profiles obtained were analysed with RAPDistance Programs Package Version 1.04 (Armstrong et al. 1994). These programs were designed to help record and analyse the RAPD (Randomly Amplified Polymorphic DNA) or RFLP (Restriction Fragment Length Polymorphism) fragment of DNA. Distances calculation of similarity band profiles was based on Dice formulation (Nei \& Li 1979). By this analysis, the degree of similarity among the strains was studied. A distance matrix value, $D$ value, of 0 indicated identical patterns and a $D$ value of 1.0 suggested complete dissimilarity. From the calculated Dice formulation, a dendrogram of neighbour-joining tree (NJTREE) description file was achieved by means of the Tdraw clustering algorithm program.

\section{Results}

Chromosomal DNA was digested with $X b a \mathrm{I}$ and yielded between 10 and 18 bands, with sizes of approximately $48.5-679.0 \mathrm{~kb}$. A total of 45 distinct restriction endonuclease digestion profiles (REDPs) were generated from the 51 isolates of E. coli (Table 1). Two isolates repeatedly appeared as a smear of degraded DNA (Figure 1, lane 43 and 61). These may be due to endogeneous nuclease activity. These isolates were represented as untypeable (UT). The five STEC O157:H7 isolates from a beef sample from Bintulu shared identical PFGE pattern (Figure 1, lane 2-6). Two different PFGE patterns (differing by 14 bands) were observed among four E. coli $\mathrm{O} 157$ isolates from beef samples purchased in Kuching and Kota Kinabalu, one (PFGE pattern) of which was shared by three isolates. The PFGE patterns of STEC O157:H7 and E. coli O157 isolates differed by 16-18 bands. Two non-O157 STEC isolates, with different Shiga-like toxin profiles (i.e. Figure 1, lane 13 represented STEC harbouring stxl and $s t x 2$ genes, lane 41 represented STEC harbouring st $x 2$ gene only) were found to be very different ( 21 band 
Table 1. The source and PFGE patterns of E. coli isolates.

\begin{tabular}{|c|c|c|c|}
\hline Isolate no. & Location & Serotype & PFGE pattern \\
\hline BTC11 & Bintulu & E. coli $\mathrm{O} 157: \mathrm{H} 7$ & 1 \\
\hline BTC14 & Bintulu & E. coli $\mathrm{O} 157: \mathrm{H} 7$ & 1 \\
\hline BTC15 & Bintulu & E. coli $\mathrm{O} 157: \mathrm{H} 7$ & 1 \\
\hline BTC19 & Bintulu & E. coli $\mathrm{O} 157: \mathrm{H} 7$ & 1 \\
\hline BTC20 & Bintulu & E. coli $\mathrm{O} 157: \mathrm{H} 7$ & 1 \\
\hline KCD8 & Kuching & E. coli $\mathrm{O} 157$ & 2 \\
\hline KKW1 & Kota Kinabalu & E. coli $\mathrm{O} 157$ & 3 \\
\hline KKW3 & Kota Kinabalu & E. coli $\mathrm{O} 157$ & 3 \\
\hline KKW5 & Kota Kinabalu & E. coli $\mathrm{O} 157$ & 3 \\
\hline BTE3 & Bintulu & Non-O157 STEC & 4 \\
\hline KCD32 & Kuching & Non-O157 STEC & 5 \\
\hline $\mathrm{KCD} 23$ & Kuching & E. coli (NA) & 6 \\
\hline $\mathrm{KCB} 5$ & Kuching & E. coli (NA) & 7 \\
\hline $\mathrm{KCN} 1$ & Kuching & E. coli (NA) & 8 \\
\hline $\mathrm{KCO} 5$ & Kuching & E. coli (NA) & 9 \\
\hline KCA25 & Kuching & E. coli (NA) & 10 \\
\hline KCA2 & Kuching & E. coli (NA) & 11 \\
\hline $\mathrm{KCH} 5$ & Kuching & E. coli (NA) & 12 \\
\hline KCM11 & Kuching & E. coli (NA) & 13 \\
\hline SMA2 & Samarahan & E. coli (NA) & 14 \\
\hline SMB2 & Samarahan & E. coli (NA) & 15 \\
\hline SMB3 & Samarahan & E. coli (NA) & 16 \\
\hline SAA1 & Sarikei & E. coli (NA) & 17 \\
\hline SAB1 & Sarikei & E. coli (NA) & 18 \\
\hline KKU16 & Kota Kinabalu & E. coli (NA) & 19 \\
\hline KKB8 & Kota Kinabalu & E. coli (NA) & 20 \\
\hline KKF5 & Kota Kinabalu & E. coli (NA) & 21 \\
\hline KKM6 & Kota Kinabalu & E. $\operatorname{coli}(\mathrm{NA})$ & 22 \\
\hline KKA7 & Kota Kinabalu & E. coli (NA) & 23 \\
\hline SDB1 & Sandakan & E. coli (NA) & 24 \\
\hline SDC5 & Sandakan & E. coli (NA) & 25 \\
\hline SDC10 & Sandakan & E. coli (NA) & 26 \\
\hline SDB18 & Sandakan & E. coli (NA) & 27 \\
\hline BTC4 & Bintulu & E. coli (NA) & 28 \\
\hline BTA1 & Bintulu & E. coli (NA) & 29 \\
\hline BTA14 & Bintulu & E. coli (NA) & 30 \\
\hline BTB8 & Bintulu & E. coli (NA) & 31 \\
\hline BTC9 & Bintulu & E. $\operatorname{coli}(\mathrm{NA})$ & UT \\
\hline BTF12 & Bintulu & E. coli (NA) & 32 \\
\hline SBD17 & Sibu & E. coli (NA) & 33 \\
\hline SBD11 & Sibu & E. coli (NA) & 34 \\
\hline SBF8 & Sibu & E. coli (NA) & 35 \\
\hline SBA9 & Sibu & E. coli (NA) & 36 \\
\hline MIO5 & Miri & E. coli (NA) & UT \\
\hline MIS4 & Miri & E. coli (NA) & 37 \\
\hline MIG1 & Miri & E. coli (NA) & 38 \\
\hline MIN2 & Miri & E. coli (NA) & 39 \\
\hline MIA9 & Miri & E. coli (NA) & 40 \\
\hline $\mathrm{MIC1}$ & Miri & E. $\operatorname{coli}(\mathrm{NA})$ & 41 \\
\hline MIL10 & Miri & E. coli (NA) & 42 \\
\hline MIY2 & Miri & E. coli (NA) & 43 \\
\hline SGH1 & Kuching & E. coli $\mathrm{O} 157: \mathrm{H} 7$ & 44 \\
\hline EDL933 & - & E. coli $\mathrm{O} 157: \mathrm{H} 7$ & 45 \\
\hline
\end{tabular}

- NA: not available (Serotype other than O157 and H7 was not performed).

- UT: untypeable; SF: sorbitol fermenting; GUD: $\beta$-glucuronidase activity.

- E. coli 0157 isolates were not tested for H serotype.

differences). The remaining $E$. coli isolates were assigned to 40 very different PFGE patterns.

The PFGE profiles were further analysed using the RAPDistance program and a dendrogram (Figure 2) was generated from the $E$. coli isolates. The dendrogram was constructed based on the differences of the genetic distance and distant matrix information gained from scoring the presence and absence of a band in the PFGE profile. E. coli isolates studied were grouped into five PFGE clusters, designated as cluster A-E. The lowest and highest $D$ Values were detected at 0.2000 and 0.9130 for $E$. coli isolates in cluster $\mathrm{B}$ and $\mathrm{D}$, respectively. The E. coli $\mathrm{O} 157: \mathrm{H} 7$, including STEC O157:H7 isolates from beef samples, the reference strain E. coli $\mathrm{O} 157: \mathrm{H} 7$ strain 


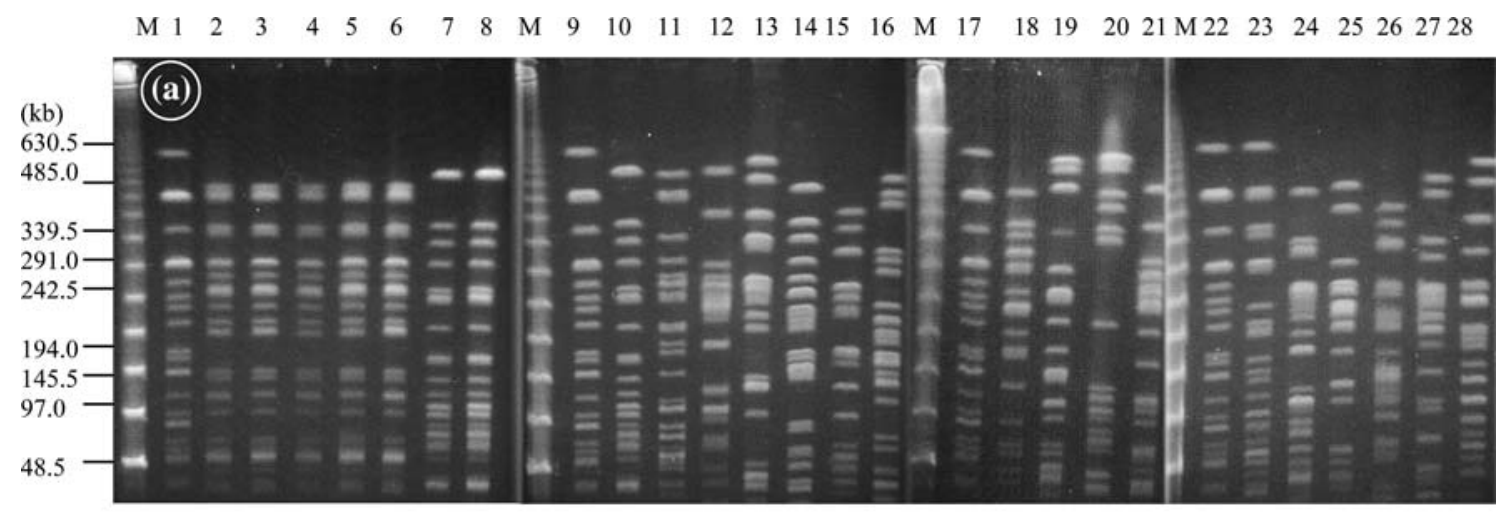

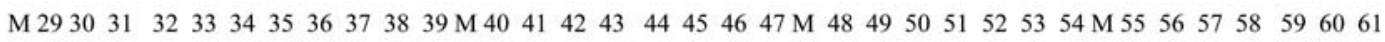

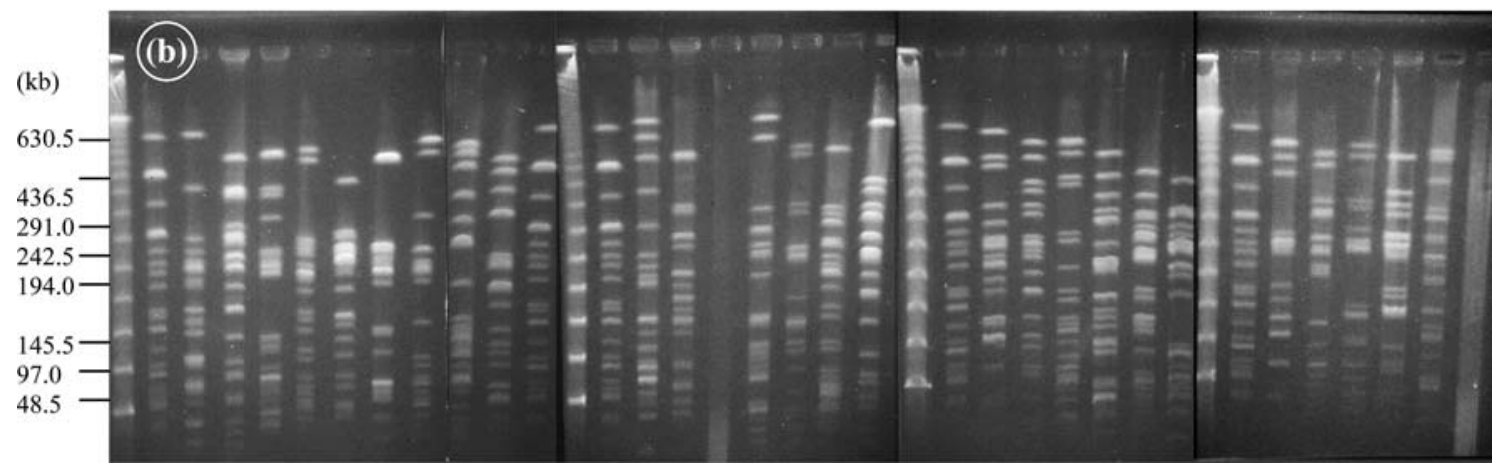

Figure 1. PFGE of chromosomal DNA digested with $X b a \mathrm{I}$ of 51 E. coli isolates with two program blocks. Lanes: M, PFG lambda ladder; 1, 9, 17, 22, 29, 39, 40, 48, 55, reference strain E. coli O157:H7 strain EDL 933; 2-6, STEC O157:H7 from Bintulu; 7, 8, 10, E. coli O157 from Kota Kinabalu; 11, E. coli O157 from Kuching; 12, E. coli from Kuching; 13, non-O157 STEC from Kuching; 14-16, 18-21, E. coli from Kuching; 23, E. coli O157:H7 strain SGH1 from clinical sample; 24-26, E. coli from Samarahan; 27-28, E. coli from Sarikei; 30-34: E. coli from Kota Kinabalu; 35-38: E. coli from Sandakan; 41, non-O157 STEC from Bintulu; 42-47, E. coli from Bintulu; 49-52, E. coli from Sibu; 53-54, 56-61: E. coli from Miri.

EDL933 and the clinical isolate E. coli O157:H7 strain SGH1, were grouped into cluster B. The E. coli $\mathrm{O} 157: \mathrm{H} 7$ beef isolates were more related to clinical isolate, SGH1 with $D$ value of 0.2353 as compared to reference strain E. coli $\mathrm{O} 157: \mathrm{H} 7$ strain EDL933 $(D$ value $=0.3939)$. There were five non-pathogenic $E$. coli isolates grouped into cluster $\mathrm{B}$, indicating some genetic relatedness to the $E$. coli O157:H7. The most closely related isolates were the seven strains of $E$. coli $\mathrm{O} 157: \mathrm{H} 7$ ( $D$ value of $0.2-0.3939$ ) within cluster B. In contrast, E. coli isolates in cluster A were shown to be the most heterogeneous. Three $E$. coli isolates grouped in cluster A were shown to have the most differences with the highest $D$ value of 0.8261 .

\section{Discussion}

PFGE has often been considered the 'gold standard' for the molecular typing of $E$. coli strains by many researchers (Izumiya et al. 1997 Preston et al. 2000; Welinder-Olsson et al. 2002), due to its high discriminatory power. The high discriminatory ability of PFGE analysis was clearly confirmed by the present study, generating 45 different REDPs on PFGE patterns of 49 E. coli strains. PFGE showed a good ability to discriminate between E. coli isolates of serogroup O157:H7 and O157, STEC and other E. coli isolated from beef marketed in East Malaysia. From the PFGE profiles and the distance matrix calculated, E. coli $\mathrm{O} 157: \mathrm{H} 7$ and E. coli O157 strains were not closely related. In addition, none of the pathogenic E. coli strains displayed close genetic relationship with the non-STEC strains. For further application, the different PFGE patterns would give invaluable information especially in the epidemiological area, whereby it is possible to assess the presence of an outbreak and to differentiate between outbreaks.

E. coli $\mathrm{O} 157: \mathrm{H} 7$ with single PFGE type was observed in this study. Five E. coli $\mathrm{O} 157: \mathrm{H} 7$ were isolated in one beef sample purchased from Bintulu. All of them were found to exhibit identical PFGE profile designated as pattern 1. This indicated that the E. coli O157:H7 positive beef sample marketed in East Malaysia, which may pose a threat to the public health, harboured only single E. coli $\mathrm{O} 157: \mathrm{H} 7$. In contrast to the result of this study, multiple PFGE types of E. coli isolates were indicated in some other studies. Kudva et al. (1997), in the characterisation of E. coli $\mathrm{O} 157: \mathrm{H} 7$ isolated from sheep had demonstrated that multiple E. coli O157:H7 strains could be simultaneously shed by a single animal. Faith et al. (1996) observed 20 distinct PFGE patterns 


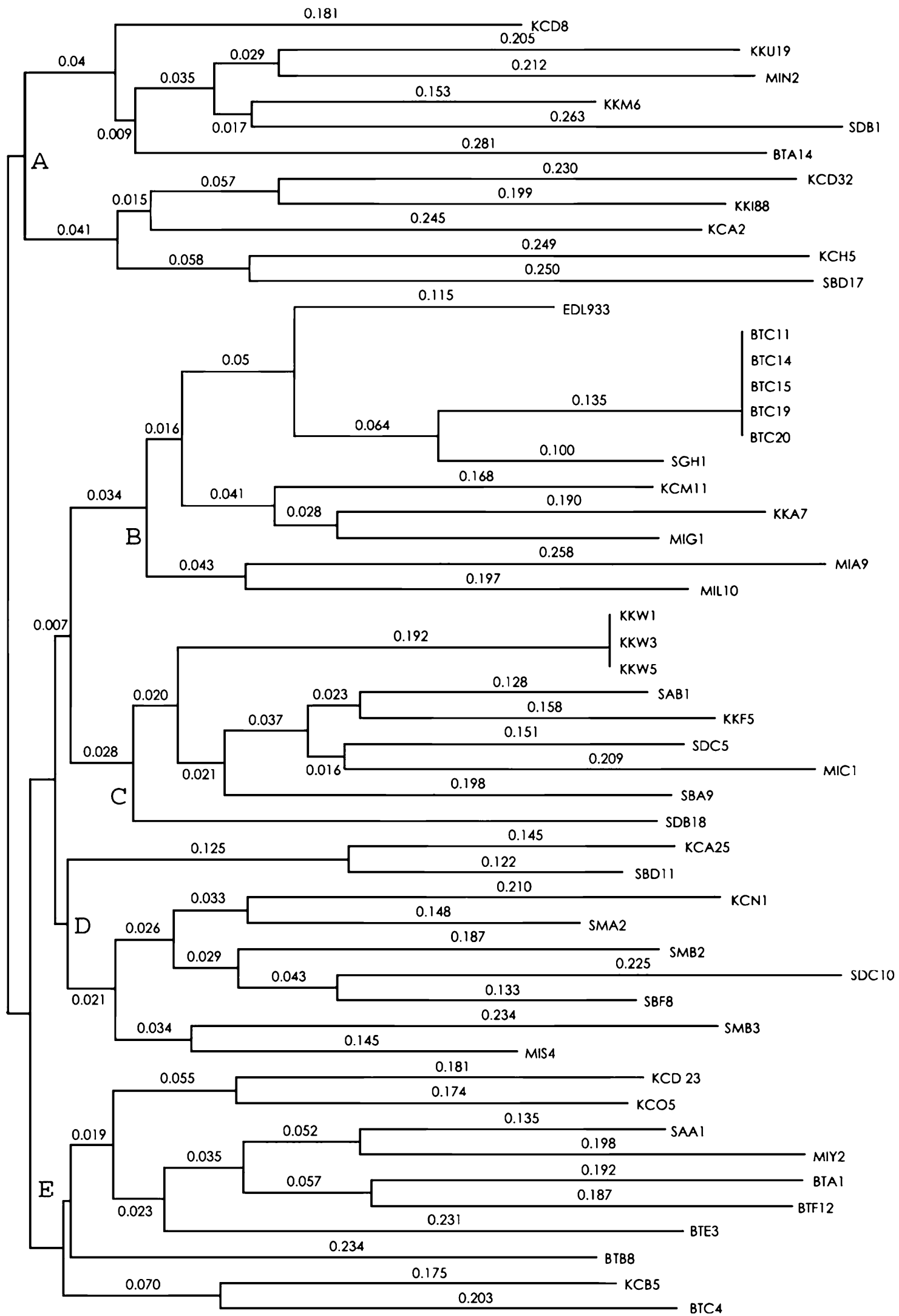

Figure 2. Dendrogram of E. coli O157:H7, E. coli O157, STEC, and E. coli strains isolated from beef marketed in East Malaysia. The dendrogram was constructed with the use of the NJTREE method by comparison of XbaI PFGE patterns. Numbers represent the distance values between the respective isolates. 
among 160 E. coli $\mathrm{O} 157: \mathrm{H} 7$ isolates from 29 cattle over an 8-month period and they indicated that individual cattle could harbour more than one E. coli $\mathrm{O} 157: \mathrm{H} 7$ strain simultaneously. Both workers attributed the existence of multiple E. coli $\mathrm{O} 157: \mathrm{H} 7$ strains in the animals to a common environmental source (water, feed, pasture) that allowed the animals to become infected with these strains, or that they were passed from one infected animal to others. The presence of several strains of E. coli $0157: \mathrm{H} 7$ would further complicate the safety of the beef consumed, and pose greater threat to consumers due to the fact that these strains are responsible for a range of disease ranging from milddiarrhea to complicated conditions such as HUS. In addition, the existence of different strains will make it difficult to determine the type of strains responsible for any outbreaks. However, our present study indicated the presence of only one serotype of E. coli O157:H7 from one beef sample, thus this will make it easier to pinpoint the strains responsible for any possible outbreak and determine the source of infection.

From the PFGE analysis, a large variety of PFGE patterns among E. coli isolates were observed, demonstrating a high $E$. coli diversity in the beef marketed in East Malaysia. The great variety of $E$. coli isolates was also demonstrated through the cluster analysis in the dendrogram, with observation of great differences in their distant matrix values (i.e. the lowest $D$ value of 0.2000 and the highest $D$ value of 0.9130 ). This is in agreement with the findings reported by Rios et al. (1999), who also reported the high diversity of Chilean isolates of EHEC of human, animal, or food origin by using XbaI PFGE typing. In the Aslam et al. (2003) study, the RAPD technique was used to study the genetic diversity of $E$. coli in beef cattle, at various stage of beef production. In this study, high genetic diversity was reported with $121 \mathrm{E}$. coli genetic subtypes being recovered from beef cattle feces, hides, carcasses and ground beef. In our study, which targeted raw beef marketed in East Malaysia, only five E. coli O157:H7 isolates from one beef sample and three E. coli $\mathrm{O} 157$ isolates showed identical PFGE patterns respectively. The remaining $41 \mathrm{E}$. coli isolates were demonstrated to have different PFGE patterns, therefore exhibiting a great genetic diversity among the $E$. coli isolates from raw beef. No clear correlation could be established between the DNA profiles and locations (towns) where the beef samples were purchased.

\section{Conclusion}

In conclusion, although the $E$. coli strains were isolated from the same type of meat (beef), considerable genetic diversity was found among the strains originating from different locations in East Malaysia. The PFGE method has been successfully used in typing both pathogenic and non-pathogenic E. coli strains isolated from beef marketed in East Malaysia. Because of its usefulness in the analysis of level of diversity among strains originating from different location, it will be a useful typing method to study the possible clonal relationship among E. coli strains and to monitor the pathway of transmission of pathogenic E. coli that may pose threat to public health.

\section{Acknowledgements}

The authors acknowledged the financial support rendered by University Malaysia Sarawak through the Short-term Grant No. 243/2001 (2), and the Ministry of Science, Technology and Environment of Malaysia's National Science Fellowship (NSF) award.

\section{References}

Apun, K., Chang, P.P., Sim, E.U.H. \& Salleh, M.A. 2003 Survey of raw beef marketed in East Malaysia for Escherichia coli 0157 and 0157:H7. Journal of Bioscience 14, 49-55.

Armstrong, J.S., Gibbs, A.J., Peakall, R. \& Weiller, G. (1994) The RAPDistance package, version 1.04. In http://www.anu.edu.au/ BoZo/software/.

Aslam, M., Nattress, F., Greer, G., Yost, C., Gill, C. \& McMullen, L. 2003 Origin of contamination and genetic diversity of Escherichia coli in beef cattle. Applied and Environmental Microbiology 69, 2794-2799.

Bettelheim, K.A 2000 Role of non-O157 VTEC. Journal of Applied Microbiology 88, 38S-50S.

Dalla-Costa, L.M., Irino, K., Rodrigues, J., Rivera, I.N.G. \& Trabulsi, L.R. 1998 Characterisation of diarrhoeagenic Escherichia coli clones by ribotyping and ERIC-PCR. Journal of Medical Microbiology 47, 227-234.

Faith, N.G., Shere, J.A., Brosch, R., Arnold, K.W., Ansay, S.E., Lee, M.-S., Luchansky, J.B. \& Kaspar, C.W. 1996 Prevalence and clonal nature of Escherichia coli $\mathrm{O} 157: \mathrm{H} 7$ on dairy farms in Wisconsin. Applied and Environmental Microbiology 62, 15191525.

Hopkins, K.L. \& Hilton, A.C. 2000 Simultaneous molecular subtyping and shiga toxin gene detection in Escherichia coli using multiplex polymerase chain reaction. Letters in Applied Microbiology 30, $122-125$.

Izumiya, H., Terajima, J., Wada, A., Inagaki, Y., Itoh, K.-I., Tamura, K. \& Watanabe, H. 1997 Molecular typing of Enterohemorrhagic Escherichia coli $\mathrm{O} 157: \mathrm{H} 7$ isolates in Japan by using pulsed-field gel electrophoresis. Journal of Clinical Microbiology 35, 1675-1680.

Khakhria, R., Duck, D. \& Lior, H. 1990 Extended phagetyping scheme for Escherichia coli O157:H7. Epidemiology and Infection 105, 511-520.

Kudva, I.T., Hatfield, P.G. \& Hovde, C.J. 1997 Characterization of Escherichia coli O157:H7 and other Shiga toxin-producing E. coli serotypes isolated from sheep. Journal of Clinical Microbiology 35, 892-899.

Nataro, J.P. \& Kaper, J.B. 1998 Diarrheagenic Escherichia coli. Clinical Microbiology Reviews 11, 142-201.

Nei, M. \& Li, W.H. 1979 Mathematical model for studying genetic variation in terms of restriction endonucleases. Proceedings of the National Academy of Sciences, USA 76, 5269-5273.

Paton, J.C. \& Paton, A.W. 1998 Pathogenesis and diagnosis of Shiga toxin-producing Escherichia coli infections. Clinical Microbiology Reviews 11, 450-479.

Preston, M.A., Johnson, W., Khakhria, R. \& Borczyk, A. 2000 Epidemiologic subtyping of Escherichia coli serogroup O157 strains isolated in Ontario by phage typing and 
pulsed-field gel electrophoresis. Journal of Clinical Microbiology 38, 2366-2368.

Rios, M., Prado, V., Trucksis, M., Arellano, C., Borie, C., Alexandre, M., Fica, A. \& Levine, M.M. 1999 Clonal diversity of Chilean isolates of enterohemorrhagic Escherichia coli from patients with hemolytic-uremic syndrome, asymptomatic subjects, animal reservoirs, and food products. Journal of Clinical Microbiology 37, 778-781.
Thong, K.L. \& Pang, T. 1996 Method: a rapid, simplified method for preparation of chromosomal DNA from pathogenic bacteria for use in PFGE. Asia Pacific Journal of Molecular Biology and Biotechnology 4, 59-62.

Welinder-Olsson, C., Badenfors, M., Cheasty, T., Kjellin, E. \& Kaijser, B. 2002 Genetic profiling of enterohemorrhagic Escherichia coli strains in relation to clonality and clinical signs of infection. Journal of Clinical Microbiology 40, 959-964. 